\title{
Erratum to: Plant species composition in green spaces within the built-up areas of Beijing, China
}

\author{
Juanjuan Zhao $\cdot$ Zhiyun Ouyang $\cdot$ Hua Zheng \\ Weiqi Zhou - Xiaoke Wang • Weihua Xu • \\ Yongming Ni
}

Published online: 9 January 2010

(C) Springer Science+Business Media B.V. 2010

\section{Erratum to: Plant Ecol \\ DOI 10.1007/s11258-009-9675-3}

Notes: Those characters in the brackets after the characters with underline were original incorrect words.

\footnotetext{
Abstract:

[1] Line 1 (the right column): A total of 611 (618) plant species belonging to

[2] Line 6 (the right column): among which $\underline{64 \%}$ $(67 \%)$ were intro-
}

\section{Results:}

[1] Paragraph 1-Line 1: A total of $\underline{611}$ (618) species belonging to 349 genera and

The online version of the original article can be found under doi:10.1007/s11258-009-9675-3.

J. Zhao $\cdot$ Z. Ouyang $(\bowtie) \cdot$ H. Zheng $\cdot$ X. Wang $\cdot$ W. Xu State Key Laboratory of Urban and Regional Ecology, Research Center for Eco-Environmental Sciences, Chinese Academy of Sciences, P.O. Box 2871, Beijing 100085, People's Republic of China e-mail: zyouyang@mail.rcees.ac.cn

\section{W. Zhou}

Department of Plant Sciences, University of California, Davis, Mail Stop 1, 1210 PES, One Shields Ave, Davis, CA 95616, USA

\section{Y. Ni}

Beijing Museum of Natural History, Tianqiao ST 126, Beijing 100050, People's Republic of China
[2] Paragraph 3-Line 1: Among the total of $\underline{611}$ (618) species, 281 (293) were native

[3] Paragraph 3-Line 2: 164 (166) were alien species from other areas of

[4] Paragraph 3-Line 3: China, 158 (142) were alien species from abroad

[5] Paragraph 3-Line 4: and 8 (17) species had no clear records of

[6] Paragraph 3-Line 5: Native species contributed $48-83 \%(41-85 \%)$ of the

[7] Paragraph 3-Line 8: 66\% (68.3\%) of the total plant cover, $77 \%(77.5 \%)$ of the total

[8] Paragraph 3-Line 9: and 72\% (74.3\%) of total plant

[9] Paragraph 3-Line 12: For example, more than $15 \%(24 \%)$ of the shrub

[10] Paragraph 3-Line 14: 18\% (15\%) of the shrub and tree species originated from

[11] Paragraph 3-Line 19: up to 46\% (45\%) and $18 \%$ of the

[12] Paragraph 3-Line 20: total number of abroad alien species (alien species)

\section{Discussion:}

[1] Paragraph 1-Line 1: While the total number of 611 (618) vascular plant

[2] Paragraph 1-Line 4: it is still $\underline{671}$ (664) species

[3] Paragraph 3-Line 1: Thirty-three (thirty$\underline{\text { seven) invasive species were recorded }}$ 